06

\title{
Влияние высокотемпературного отжига на сопротивление высокоскоростному деформированию и разрушению тантала при температуре 20 и $500^{\circ} \mathrm{C}$
}

\author{
(C) Г.В. Гаркушин, ${ }^{1}$ А.С. Савиных, ${ }^{1}$ С.В. Разоренов, ${ }^{1}$ Г.И. Канель ${ }^{2}$ \\ ${ }^{1}$ Институт проблем химической фризики РАН, \\ 142432 Черноголовка, Россия \\ ${ }^{2}$ Объединенный институт высоких температур РАН, \\ 125412 Москва, Россия \\ e-mail: garkushin@ficp.ac.ru
}

Поступило в Редакцию 27 июня 2018 г.

В окончательной редакции 25 октября 2018 г.

Принято к публикации 25 октября 2018 г.

\begin{abstract}
Проведены две серии ударно-волновых экспериментов по измерению динамического предела упругости и зависимости критических разрушающих напряжений от скорости деформирования при откольном разрушении тантала марки ТВЧ-1 после предварительного отжига в вакууме при температуре $1000^{\circ} \mathrm{C}$. Представлены результаты измерений эволюции упругопластических волн ударного сжатия при комнатной и повышенной до $500^{\circ} \mathrm{C}$ температурах, полученные путем анализа полных волновых профилей, зарегистрированных с помощью лазерного доплеровского измерителя скорости VISAR. Определена зависимость откольной прочности от скорости деформирования при расширении материала в волне разрежения.
\end{abstract}

DOI: 10.21883/JTF.2019.05.47475.253-18

\section{Введение}

Интерес к изучению прочностных свойств тантала при ударном нагружении основан прежде всего на его уникальных физических свойствах - высокой жаропрочности (температура плавления около $3000^{\circ} \mathrm{C}$ ), коррозионной стойкости (тантал практически не реагирует с другими материалами), механических свойствах (при высокой прочности тантал имеет высокую пластичность) и т.д. Такой уникальный набор свойств обусловливает его широкое практическое использование, в том числе в изделиях и конструкциях, подвергаемых высокоинтенсивным импульсным воздействиям. Для прогнозирования результатов такого рода воздействий необходимы сведения о сопротивлении материала высокоскоростному деформированию и разрушению и соответствующие определяющие соотношения, пригодные для использования при расчетах его поведения в широком диапазоне скоростей деформации и температур. Анализ эволюции упругопластических волн ударного сжатия в исследуемых материалах позволяет получать с высокой точностью необходимую информацию в диапазоне скоростей деформации $10^{3}-10^{7} \mathrm{~s}^{-1}$. Исследованию тантала при ударно-волновом нагружении посвящено большое количество работ, в частности $[1-8]$, которые, однако, дают сильный разброс прочностных характеристик даже близких по составу образцов. Так, например, динамический предел упругости тантала по разным данным варьируется от 2 до $4 \mathrm{GPa}$, откольная прочность - от 5 до $10 \mathrm{GPa}$. В работе[4] проведены исследования упругопластических и прочностных свойств технически чистого тантала в условиях ударно-волнового нагружения при комнатной температуре с разной дефектной структурой как в крупнокристаллическом, так и мелкозернистом состояниях. Там же приведены результаты исследования монокристаллического тантала и показано, что наибольшие разрушающие напряжения при отколе реализуются в тантале с монокристаллической структурой.

Настоящая работа посвящена исследованию эволюции ударных волн сжатия в отожженных образцах тантала в условиях ударно-волнового нагружения. Проведено исследование процесса затухания динамического предела упругости при различных температурах образцов, и получена зависимость динамической прочности тантала от скорости деформирования в волне разгрузки. Измерения основываются на том факте, что процессы упругопластического деформирования и разрушения, сопровождающие ударно-волновое воздействие на твердое тело, приводят к появлению специфических особенностей в структуре и эволюции волн сжатия и разрежения.

\section{Материал и постановка эксперимента}

В настоящей работе проведены ударно-волновые испытания тантала марки ТВЧ1 с содержанием тантала 99.7\% при температуре 20 и $500^{\circ} \mathrm{C}$. Тантал имеет ОЦК-кристаллическую решетку плотностью $16650 \mathrm{~kg} / \mathrm{m}^{3}$ с температурой плавления $2996^{\circ} \mathrm{C}$. Ограничения по температуре в этих экспериментах связаны с потерей отражающей способности поверхности образцов лазерного зондирующего излучения в процессе регистрации волновых профилей лазерным интерферометром при их нагревании выше температуры $500^{\circ} \mathrm{C}$, поскольку все ударно-волновые эксперименты проводились 


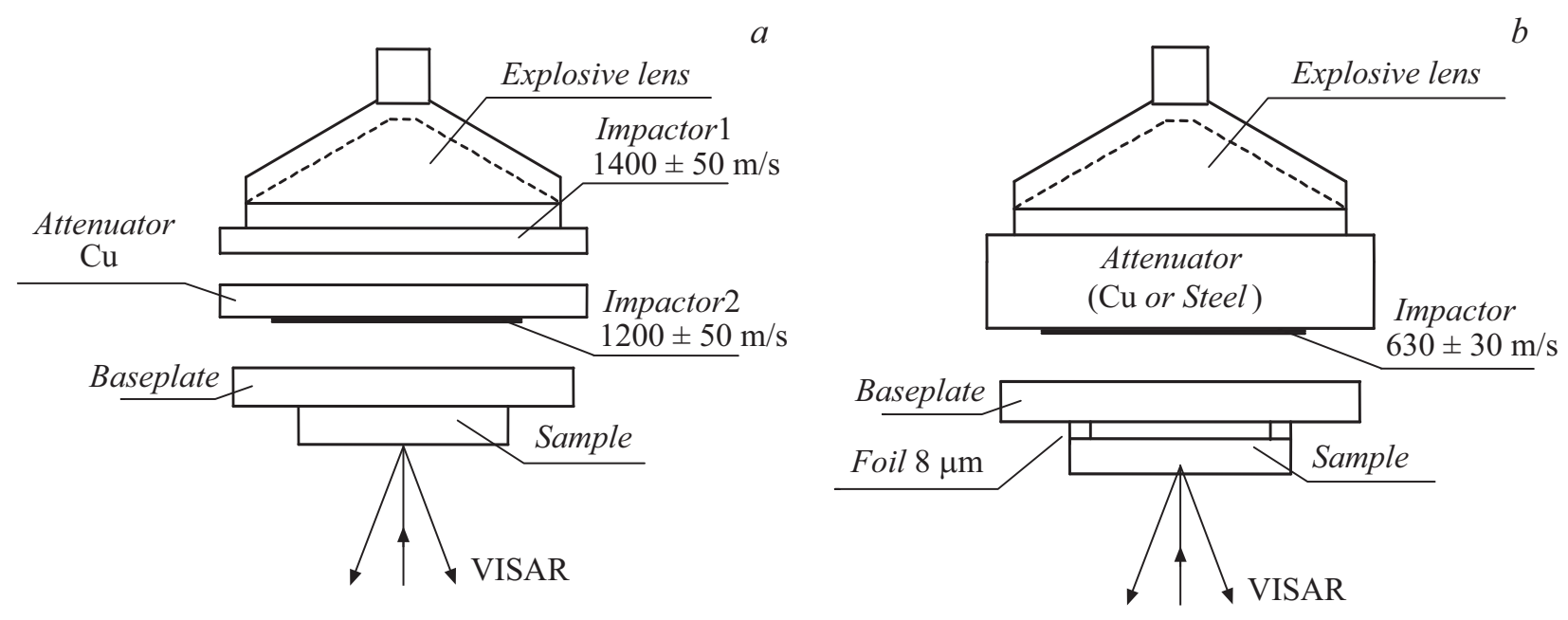

Рис. 1. Схемы нагружения образцов тантала.

на воздухе. Заготовки образцов тантала были подвергнуты предварительному отжигу при температуре $1000^{\circ} \mathrm{C}$ в течение двух часов в условиях высокого вакуума. Цель отжига заключалась в снятии внутренних напряжений в образцах и гомогенизации их микроструктуры. Для оценки влияния отжига на характеристики тантала перед ударно-волновыми экспериментами были измерены твердость и продольные скорости звука $c_{l}$ исходных и отожженных образцов. Средняя твердость образцов до отжига составляла $99 \pm 2 \mathrm{HRF}$, а после отжига уменьшалась до величины $80 \pm 2 \mathrm{HRF}$. Уменьшение твердости связано с уменьшением плотности дефектов структуры, облегчающее скольжение дислокаций, что в свою очередь приводит к снижению твердости материала. Измеренные скорости звука составляли 4190 и $4150 \mathrm{~m} / \mathrm{s}$ соответственно.

Плоскопараллельные образцы для опытов вырезались на электроэрозионном станке в виде дисков диаметром 12-15 mm, толщина которых варьировалась в диапазоне от 0.17 до $5 \mathrm{~mm}$. Измерения динамической (откольной) прочности и динамического предела упругости образцов проводились при их нагружении плоскими ударными волнами, интенсивность которых не превышала $14 \mathrm{GPa}$. Ударные волны генерировались с помощью взрывных устройств двух типов, позволяющих разгонять алюминиевые пластины ударники до скоростей $1200 \pm 50$ и $630 \pm 30 \mathrm{~m} / \mathrm{s}$ [9]. Схемы экспериментальных сборок представлены на рис. $1, a, b$. Для исследования процессов откольного разрушения при различных скоростях деформирования перед разрушением использовался метод разгона тонких ударников различной толщины до скорости $1200 \pm 50 \mathrm{~m} / \mathrm{s}$ с использованием промежуточного медного ослабителя толщиной $5.5 \mathrm{~mm}$ (рис. 1,a).

Алюминиевый ударник 1 толщиной $4 \mathrm{~mm}$ разгонялся ударной волной, формируемой плосковолновой взрывной линзой, до скорости $\sim 1400 \pm 50 \mathrm{~m} / \mathrm{s}$. Тонкие алюминиевые ударники, генерирующие ударную волну в образце, располагались на медном ослабителе и отрыва- лись от него после выхода ударной волны на свободную поверхность ударника вследствие разницы динамических импедансов $\rho c$ ( $\rho-$ плотность материала, $c-$ скорость звука в нем) этих металлов. Толщина алюминиевых ударников в проведенных экспериментах варьировалась в диапазоне от 0.05 до $0.850 \mathrm{~mm}$, толщина образцов изменялась соответственно от 0.18 до $3 \mathrm{~mm}$. Соотношение толщин образцов и ударников составляло 4-5, что позволяло формировать в нагружаемом образце импульс сжатия треугольной формы, что в свою очередь обеспечивало наиболее точные измерения критических разрушающих напряжений при отколе.

Для исследования процесса затухания упругого предвестника в танталовых образцах использовалась несколько другая схема нагружения, показанная на рис. $1, b$. В этих экспериментах для исключения влияния на эволюцию профиля волны сжатия при выходе последней на свободную поверхность образца слабой воздушной волны сжатия, формирующейся при разгоне пластины-ударника, плоская ударная волна от взрывной линзы распространялась в образец через $2 \mathrm{~mm}$, алюминиевый экран с $8 \mu \mathrm{m}$ воздушным зазором. Толщина алюминиевых ударников во всех экспериментах была $2 \mathrm{~mm}$, толщина образцов изменялась соответственно от 0.2 до $5 \mathrm{~mm}$. Для испытаний при повышенных температурах использовались резистивные нагреватели мощностью до $1 \mathrm{~kW}$, вмонтированные в специальные керамические формы [10], что позволяло нагревать образцы до необходимой температуры в течение $10 \mathrm{~min}$ или менее. Температура контролировалась в непосредственной близости от оси удара с помощью хромельалюмелевой термопары, точность измерений которой составляла $\pm 5^{\circ} \mathrm{C}$. Для регистрации полных волновых профилей (зависимостей скорости свободной поверхности от времени $\left.u_{f s}(t)\right)$ использовался лазерный доплеровский измеритель скорости VISAR [11]. Профили скорости свободной поверхности фиксировались с разрешением $1 \mathrm{~ns}$ по времени и $\pm 3 \mathrm{~m} / \mathrm{s}$ по величине измеряемой 
скорости. Анализ полных волновых профилей позволяет получать не только качественную информацию о протекающих в материале процессах, связанных с ударноволновым нагружением, но и рассчитать количественные характеристики параметров ударных волн и прочностные характеристики исследуемого материала. При анализе экспериментальных данных использовалась ударная адиабата тантала в виде линейного соотношения между скоростью ударной волны $U_{s}$ и массовой скоростью $u_{p}$ : $U_{s}=3414+1200 u_{p} \mathrm{~m} / \mathrm{s}[12]$.

\section{Результаты измерений и их обсуждение}

На рис. 2 представлены результаты опытов с образцами тантала толщиной $2.01 \mathrm{~mm}$, где сравнивается поведение образцов тантала ТВЧ1 в состоянии поставки и образцов после предварительного высокотемпературного отжига. Влияние отжига исследовалось при фиксированных условиях ударно-волнового нагружения, когда импульсы сжатия в образцах создавались ударом алюминиевой пластины толщиной $2 \mathrm{~mm}$ через алюминиевый экран 2 со скоростью $630 \pm 30 \mathrm{~m} / \mathrm{s}$. Давление ударного сжатия тантала в этих экспериментах не превышало $9.5 \mathrm{GPa}$.

При сравнении волновых профилей видно различие структуры волны сжатия и характера течения между фронтами упругой и пластической волн, что говорит об изменении реологических свойствах материала в результате отжига. Сжатие происходит монотонным образом без формирования пиков напряжения. На вставке рис. 2 представлены начальные участки волновых профилей в нормализованных координатах $u_{f s}(t / h)$, где $t-$ время в наносекундах, $h$ - толщина образца в миллиметрах. Видно, что в образце тантала после отжига четко фиксируется расщепление ударной волны на упругий предвестник (обозначено стрелкой) с напряжением сжатия за фронтом, равным динамическому пределу упругости (в общепринятой англоязычной аббревиатуре - HEL).

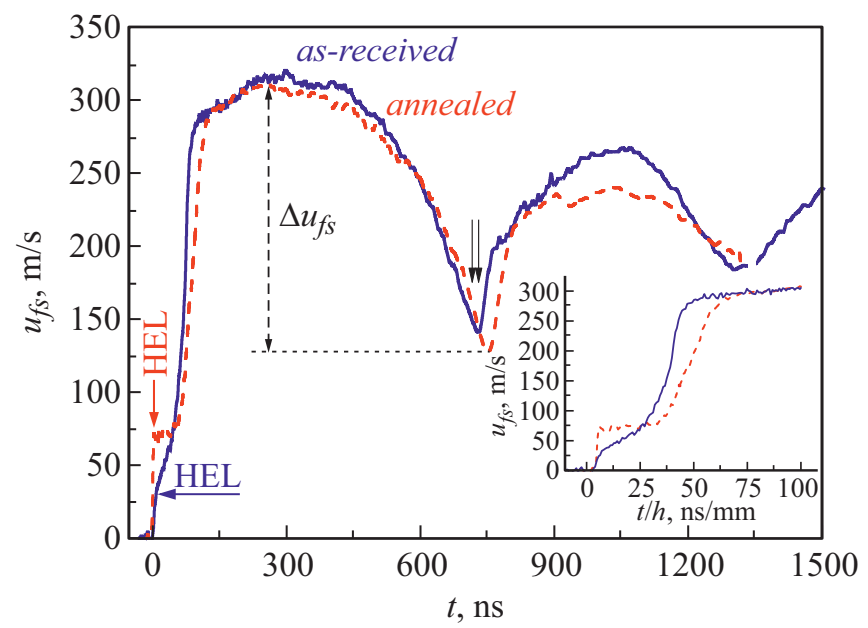

Рис. 2. Сравнение профилей скорости свободной поверхности образцов тантала в исходном и отожженном состояниях.
Другой характер упругопластического поведения демонстрирует образец в состоянии поставки, что, возможно, связано с дисперсией скорости звука. Отжиг материала привел к уменьшению дефектности структуры, а также плотности подвижных дислокаций, вследствие чего для обеспечения высокой скорости деформации требуется более высокие значения скорости движения дислокаций и соответственно более высокие значения действующих напряжений. В результате динамический предел упругости в отожженном материале оказался более высоким. Поэтому вклад процессов размножения дислокаций в скорость пластической деформации становится более важным в отожженном материале. Подобный эффект отжига ранее наблюдался в работах [13] с титаном ВТ1-0. Кроме того, при сопоставлении волновых профилей на рис.2 в нормализованных координатах явно наблюдаются изменения времени нарастания в пластической ударной волне и также рост временных интервалов между выходом на свободную поверхность упругой и пластической волн.

Упругий предвестник распространяется со скоростью немного большей, но близкой к продольной скорости звука в материале $c_{l}$. Вслед за предвестником распространяется пластическая ударная волна. Ее минимальная скорость близка к объемной скорости звука $c_{b}=\sqrt{K / \rho}<c_{l} \quad(K-$ модуль объемной упругости, $\rho$ - плотность материала). Время нарастания параметров в пластической ударной волне определяется вязкостью материала или временем релаксации напряжений. Величина динамического предела упругости, определяемая по амплитуде упругой волны сжатия как $\sigma_{H E L}=\rho_{0} c_{l} u_{f s}^{H E L} / 2$, соответствует условиям одноосной деформации; и ее пересчет к пределу текучести в стандартных условиях одноосно-напряженного состояния $\sigma_{T}$ производится с использованием простого соотношения [14]:

$$
\sigma_{T}=\frac{3}{2} \sigma_{H E L}\left(1-c_{b}^{2} / c_{l}^{2}\right)
$$

Вслед за упругопластической волной сжатия на поверхность образца выходит с некоторой задержкой волна разрежения, в которой скорость поверхности уменьшается (рис. 2). Длительность задержки определяется временем реверберации волн в ударнике. После отражения импульса сжатия от свободной поверхности образца внутри его в результате интерференции падающей и отраженной волн разрежения генерируются растягивающие напряжения, при достижении критических значений которых инициируется его разрушение - откол (момент откольного разрушения обозначен двойной стрелкой на рис. 2). При этом происходит релаксация растягивающих напряжений, и формируется волна сжатия откольный импульс, выход которого на поверхность образца вызывает второй подъем ее скорости. Дальнейшие реверберации откольного импульса в откольной пластине приводят к затухающим осцилляциям скорости свободной поверхности. Как следует из анализа методом 

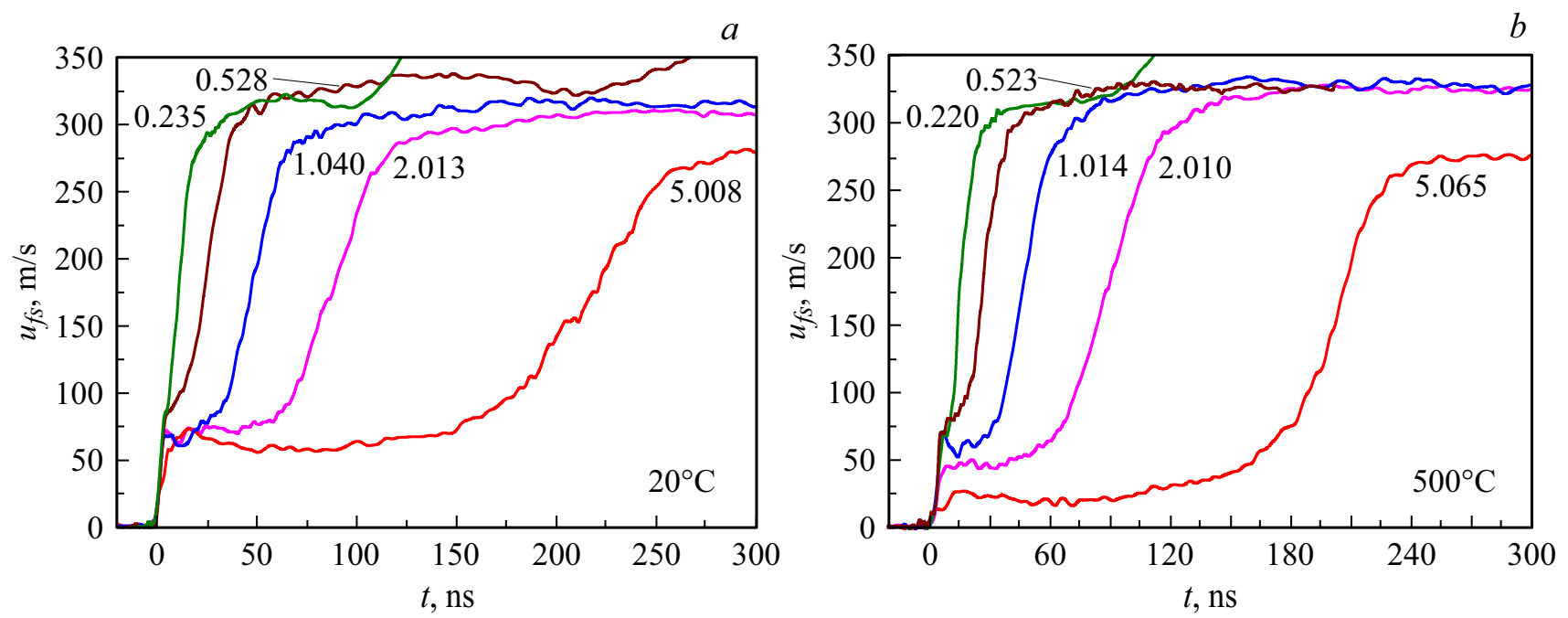

Рис. 3. Фронтальные части профилей скорости свободной поверхности образцов после отжига различной толщины при комнатной $(a)$ и при повышенной $(b)$ температуре. Толщины исследуемых образцов $(\mathrm{mm})$ указаны возле волновых профилей.

характеристик, величина растягивающих напряжений непосредственно перед откольным разрушением, называемая откольной прочностью материала, пропорциональна величине декремента скорости свободной поверхности $\Delta u_{f s}$ от ее максимального значения до значения непосредственно перед фронтом откольного импульса (рис. 2). В линейном (акустическом) приближении величина откольной прочности $\sigma_{s p}$ рассчитывается как [14]:

$$
\sigma_{s p}=\frac{1}{2} \rho_{0} c_{b}\left(\Delta u_{f s}+\delta\right),
$$

где $\delta$ - поправка на искажение профиля скорости вследствие различия скорости фронта откольного импульса, равной $c_{l}$, и скорости пластической части падающей волны разгрузки перед ним, движущейся с объемной скоростью звука $\left(c_{b}\right)$ [15]. Рассчитанные значения откольной прочности в образцах до и после отжига составляют 5.9 и $6.1 \mathrm{GPa}$ соответственно, т. е. влияние отжига на откольную прочность материала мало. Скорость деформирования непосредственно перед разрушением в этих образцах составляла $1.2 \cdot 10^{5} \mathrm{~s}^{-1}$. Сформированная в результате разрушения волна сжатия (откольный импульс) представляет собой резкий скачек параметров, имеет ярко выраженный характер и слабо затухает при ее реверберации в откольной пластине, что обусловлено тем, что внутренняя поверхность откольной пластины достаточно гладкая. А именно в данном случае можно говорить о квазихрупком процессе откольного разрушения тантала в отличие от вязких металлов, где наблюдается формирование сильно развитых поверхностей откола и быстрое затухание осцилляций скорости откольной поверхности при реверберации откольного импульса [16,17].

Эксперименты по исследованию процесса затухания упругого предвестника при нормальной и повышенной температурах проводили на отожженных образцах тантала. Нужно отметить, что они были организованы

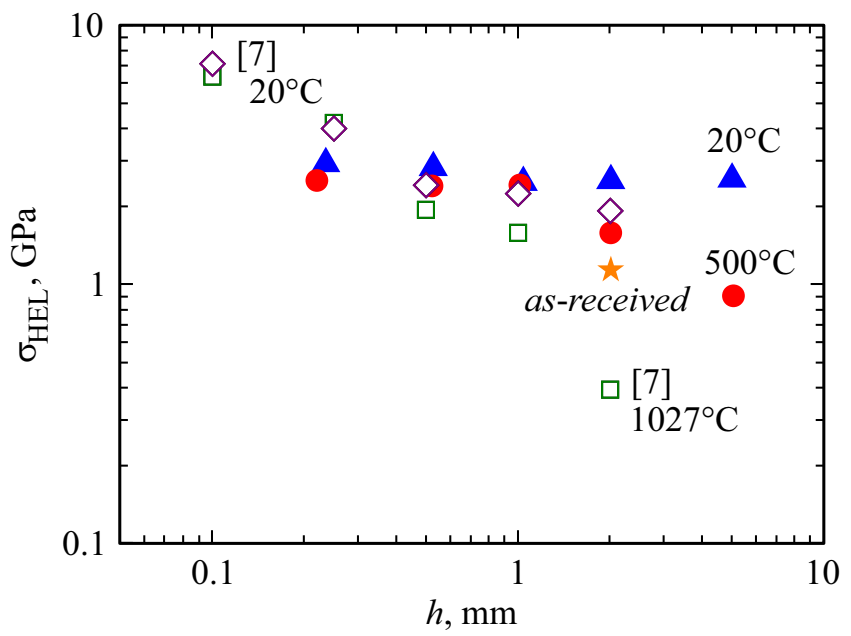

Рис. 4. Затухание упругого предвестника в образцах тантала ТВЧ1 различной толщины после отжига при комнатной и повышенной температурах и сравнение полученных результатов по затуханию упругого предвестника тантала с данными [7]. Звездочкой отмечено значение для исходного образца.

таким образом, чтобы зарегистрировать с максимальной точностью фронт упругопластической волны сжатия, в них не регистрировалась волна разгрузки и связанное с ней откольное разрушение образца. На рис. 3 представлены результаты опытов по затуханию упругих предвестников с образцами тантала после отжига толщиной от 0.2 до $5 \mathrm{~mm}$ при температуре 20 и $500^{\circ} \mathrm{C}$. Видно, что все профили демонстрируют формирование двухволновой конфигурации волны сжатия вследствие упругопластического перехода, но при комнатной температуре влияние толщины образцов на амплитуду упругого предвестника заметно меньше, чем в нагретых образцах. 
Таблица 1. Измеренные значения динамического предела упругости

\begin{tabular}{c|c|c}
\hline$T,{ }^{\circ} \mathrm{C}$ & $h_{\text {sample }}, \mathrm{mm}$ & $\sigma_{H E L}, \mathrm{GPa}$ \\
\hline 20 & 0.235 & 2.9 \\
20 & 0.528 & 2.83 \\
20 & 1.040 & 2.48 \\
20 & 2.013 & 2.52 \\
20 & 5.008 & 2.55 \\
490 & 0.220 & 2.52 \\
496 & 0.523 & 2.40 \\
502 & 1.014 & 2.42 \\
506 & 2.010 & 1.58 \\
499 & 5.065 & 0.9
\end{tabular}

На рис. 4 представлены зависимости динамического предела упругости, рассчитанные по приведенным профилям скорости, от толщины образцов при комнатной и повышенной до $500^{\circ} \mathrm{C}$ начальных температурах в сопоставлении с данными, полученными в работе [7]. Влияние температуры на величину $c_{l}$ оценивалось на основании зависимости модуля сдвига от температуры по данным работы [18], где приведено экспериментальное значение температурной производной модуля сдвига $\partial G / \partial T=-9 \mathrm{MPa} / \mathrm{K}$ и обобщенная оценка этой величины, составляющая $-8.6 \mathrm{MPa} / \mathrm{K}$. Температурная производная объемного модуля сжатия $K$ определялась как $\partial K / \partial T \approx-K \alpha(\partial K / \partial p-\Gamma)$, где $\partial K / \partial p=3.15$, параметр Грюнайзена $\Gamma=1.74$, объемный коэффициент теплового расширения $\alpha=(6.8 \pm 0.4) \cdot 10^{-6} 1 / \mathrm{K}$. При комнатной температуре в отожженных образцах тантала ТВЧ1 наблюдается слабовыраженное уменьшение амплитуды упругого предвестника в исследуемом интервале их толщин. Повышение их температуры до $500^{\circ} \mathrm{C}$ приводит к незначительному уменьшению динамического предела упругости при толщинах образцов до $1 \mathrm{~mm}$. В более толстых образцах при повышенной температуре происходит сильное затухание упругого предвестника, как это видно из рис. 4. При максимальной толщине образца $5 \mathrm{~mm}$ величина динамического предела упругости уменьшается практически в 2.5 раза по сравнению с его значением для образца толщиной $1 \mathrm{~mm}$. В табл. 1 представлены результаты расчета динамического предела упругости тантала из волновых профилей.

С отожженными образцами проведена серия экспериментов по измерению зависимости откольной прочности тантала от скорости деформирования при комнатной температуре. На рис. 5 представлены профили скорости свободной поверхности, полученные в этих экспериментах.

Разброс максимального давления при одной и той же постановке экспериментов может быть связан с разным по скорости затуханием импульса сжатия в образце чем короче импульс сжатия, тем быстрее идет процесс затухания ударной волны, как это видно из эксперимента с самым тонким образцом. Второй причиной может быть небольшой разброс скорости соударения тонких алюминиевых ударников с образцом, особенно заметный при метании тонких фольг микронной толщины. На рис. 6 представлена зависимость откольной прочности тантала ТВЧ1 от скорости деформирования, полученная из обработки волновых профилей (рис. 5), в сравнении с известными литературными данными. Под скоростью деформирования здесь понимается скорость расширения вещества в волне разрежения, определяемая как $\dot{V} / V_{0}=-\dot{u}_{f s} / 2 c_{b}$, где $\dot{u}_{f s}-$ измеренная скорость спада скорости свободной поверхности испытуемого образца в разгрузочной части импульса ударного сжатия. Из рис. 6 видно, что с увеличением скорости деформирования в ударных экспериментах примерно на порядок величина сопротивления тантала откольному разрушению значительно возрастает. Здесь же показано значение временного напряжения $\sigma_{b}-$ прочности тантала на растяжение, полученной при квазистатических нагруз-

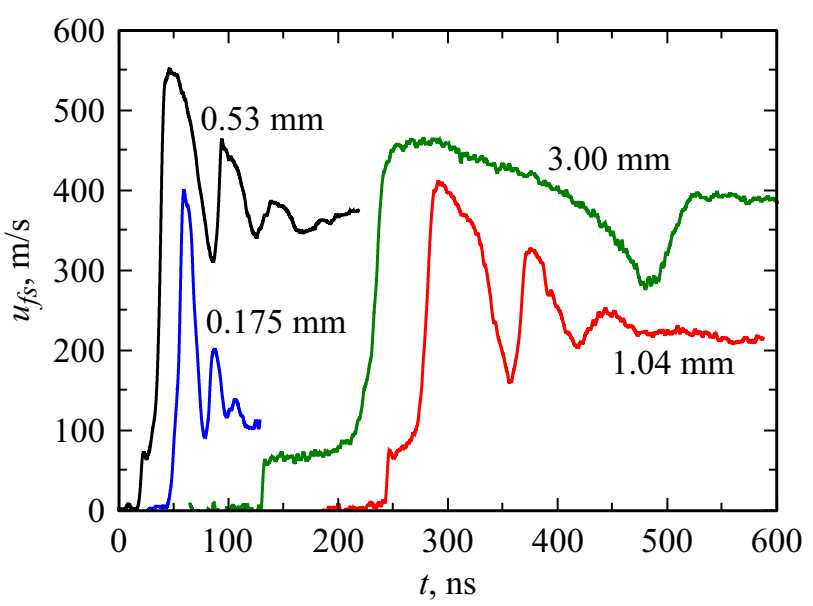

Рис. 5. Профили скорости свободной поверхности тантала ТВЧ1 при различной длительности импульса сжатия. На рисунке указаны толщины образцов.

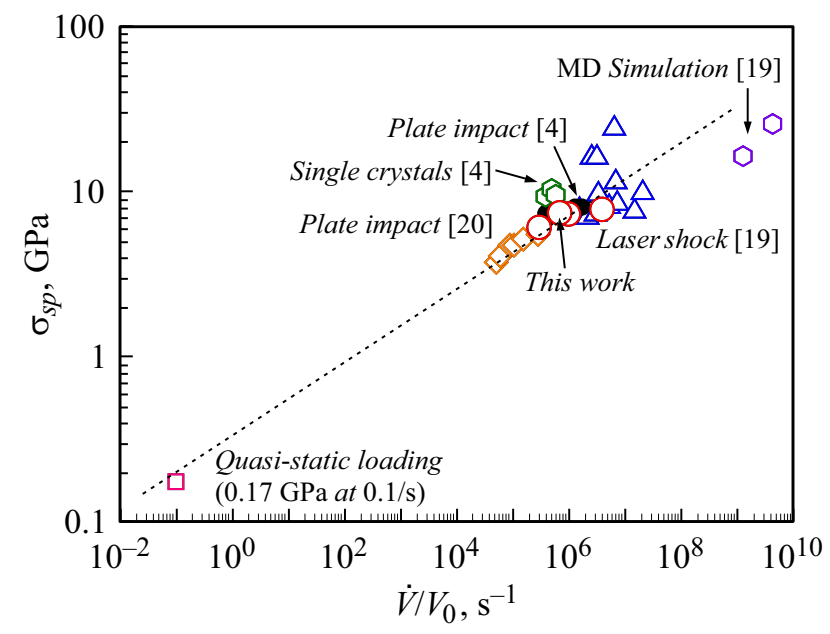

Рис. 6. Результаты измерения откольной прочности $\sigma_{s p}$ тантала в зависимости от скорости деформирования в волне разрежения (кружки). 
Таблица 2. Измеренные значения откольной прочности образцов тантала

\begin{tabular}{c|c|c|c|c}
\hline$h_{\text {sample }}, \mathrm{mm}$ & $h_{\text {imp }}, \mathrm{mm}$ & $P_{\max }, \mathrm{GPa}$ & $\dot{V} / V_{0}, 10^{6} \mathrm{~s}^{-1}$ & $\sigma_{s p}, \mathrm{GPa}$ \\
\hline 0.175 & 0.050 & 10.8 & 4 & 7.84 \\
0.530 & 0.085 & 17.2 & 1 & 7.35 \\
1.040 & 0.200 & 12.4 & 0.7 & 7.45 \\
3.000 & 0.850 & 14.2 & 0.3 & 6.10
\end{tabular}

ках. В табл. 2 приведены параметры экспериментов и значения откольной прочности тантала, рассчитанные из профилей скорости свободной поверхности, представленных на рис. 5.

\section{Заключение}

Проведенные эксперименты продемонстрировали влияние высокотемпературного отжига на сопротивление высокоскоростному деформированию тантала. Эффект более выражен на начальном этапе распространения упругопластической волны ударного сжатия, где скорость пластической деформации за фронтом упругого предвестника наиболее высока. На этом этапе из-за недостаточной плотности подвижных дислокаций динамический предел упругости отожженного материала превышает предел упругости образцов тантала в состоянии поставки. Исследования эволюции волны сжатия в области упругопластического перехода демонстрируют не только различия в амплитуде упругого предвестника, но и в характере перехода от упругого деформирования к пластическому. Измерения откольной прочности отожженного тантала в диапазоне скоростей деформирования $10^{5}-10^{6} \mathrm{~s}^{-1}$ показали, что, как и в случае других металлов, критические разрушающие напряжения в тантале возрастают с уменьшением длительности ударной нагрузки.

Работа выполнена по теме Государственного задания, № гос. регистрации 0089-2014-0016, и в рамках Программы Президиума РАН „Конденсированное вещество и плазма при высоких плотностях энергии“ по теме научного направления „Быстрые физико-химические превращения и разрушение твердых тел и жидкостей“ с использованием оборудования Московского регионального взрывного центра коллективного пользования РАН.

\section{Список литературы}

[1] Isbell W.M., Christman V.R., Babcock S.G. Measurements of dynamic properties of materials Volume VI: Tantalum. Final report., N MSL-70-23, Vol. VI. 1971. 88 p.

[2] Furnish M.D., Reinhart W.D., Trott W.M., Chhabildas L.C., Vogler T.J. In: // SCCM - 2005. / Ed.: Furnish M.D., Elert M.L., Russell T.P., White C.T. AIP Conf. Proc. 845 (1). 2006. P. 615. DOI: $10.1063 / 1.2263397$
[3] Asay J.R., Ao T., Vogler T.J., Davis J.-P., Gray III G.T. // JAP. 2009. Vol. 106. P. 073515. DOI: $10.1063 / 1.3226882$

[4] Разоренов С.В., Канель Г.И., Гаркушин Г.В., Игнатова О.Н. // ФТТ. 2012. Т. 54. Вып. 4. С. 742-749. [Razorenov S.V., Kanel G.I., Garkushin G.V., Ignatova O.N. // Phys. Solid State. 2012. Vol. 54. P. 790-797. DOI: $10.1134 / \mathrm{S} 1063783412040233]$

[5] Hammel B., Swift D.C., El-Dasher B., Kumar M., Collins G., Florando J. In: // SCCM-2011. // Ed.: Furnish M.D., Elert M.L. AIP Conf. Proc. 1426 (1). 2012. P. 931. DOI: $10.1063 / 1.3686430$

[6] Гаркушин Г.В., Игнатова О.Н., Подуреи, А.М., Разоренов С.B. // Деформация и разрушение материалов. 2013. T. 4. C. 33-40.

[7] Zaretsky E.B., Kanel G.I. // Jpn. 2014. Vol. 115. P. 243502. DOI: $10.1063 / 1.4885047$

[8] Asay J.R., Vogler T.J., Ao T., Ding J.L. // JAP. 2011. Vol. 109. P. 073507. DOI: $10.1063 / 1.3562178$

[9] Канель Г.И., Разоренов С.В. Ударно-волновое нагружение металлов. Движение поверхности образца. Черноголовка, 1989. $101 \mathrm{c}$.

[10] Патент на изобретение № 2497096 от 27.10.2013. Устройство для регистрации профилей скорости свободной поверхности при повышенных температурах.

[11] Barker L.M., Hollenbach R.E. // JAP. 1972. Vol. 43. N 11. P. 4669. DOI: $10.1063 / 1.1660986$

[12] McQueen R.G., Marsh S.P. Report N GMX-6-566, Los Alamos Sci. Lab. 1964. p. 51.

[13] Канель Г.И., Разоренов С.В., Гаркушин Г.В., Павленко А.В., Малюгина С.Н. // ФТТ. 2016. Т. 58. Вып. 6. C. 1153-1160. [Kanel G.I., Razorenov S.V., Garkushin G.V., Pavlenko A.V., Malyugina S.N. // Phys. Solid State. 2016. Vol. 58. N 6. P. 1191-1198. DOI: $10.1134 / \mathrm{S} 1063783416060202]$

[14] Канель Г.И., Разоренов С.В., Уткин А.В., Фортов В.Е. Ударно-волновые явления в конденсированных средах. М.: Янус-К, 1996. 408 с.

[15] Канель Г.И. // ПМТФ. 2001. Т. 42. Вып. 2. С. 194-198. [Kanel G.I. // J. Appl. Mechan. Techn. Phys. 2001. Vol. 42. P. 358. DOI: 10.1023/A:1018804709273]

[16] Гаркушин Г.В., Разоренов С.В., Канель Г.И. // ЖТФ. 2008. T. 78. Вып. 11. C. 53-59. [Garkushin G.V., Razorenov S.V., Kanel G.I. // Tech. Phys. 2008. Vol. 53. N 11. P. 1441. DOI: $10.1134 / \mathrm{S} 1063784208110078]$

[17] Огородников В.А., Боровкова Е.Ю., Ерунов С.В. // ФГВ. 2004. Т. 40. Вып. 5. С. 109-117. [Ogorodnikov V.A., Borovkova E.Y., Erunov S.V. // Combustion, Explosion, and Shock Waves. 2004. Vol. 40. P. 597. DOI: 10.1023/B:CESW.0000041413.64269.1c]

[18] Guinan M.W., Steinberg D.J. // J. Phys. Chem. Sol. 1974. Vol. 35. P. 1501-1512. DOI: 10.1016/S0022-3697(74)80278-7

[19] Cuq-Lelandias J.P., Boustie M., Soulard L., Berthe L., Resseguier T.De, Combis P., Bontaz-Carion J., Lescoute E. RPJ Web of Conferences. 2010. Vol. 10. P. 00014. DOI: $10.1051 /$ epjconf/20101000014

[20] Roy G. Thesis of doctor of sciences. Vers une mod élisation approfondie de l'endommagement ductile dynamique. Investigation expérimentale d'une nuance de tantale et développements théoriques. Université de Poitiers, 2003. 